\section{ANOVR: Analysis of variance with repeated measures}

\author{
P. A. GAMES, G. S. GRAY, and W. L. HERRON \\ Pennslyvania State University, University Park, \\ Pennsylvania 33620 \\ and \\ G. F. PITZ \\ Southern Ilinois University, Carbondale, Mlinois 62901
}

\section{Description}

ANOVR will analyze designs with up to four betweensubjects factors and up to four within-subjects factors, thus permitting up to eight experimental factors. Input is like that of BMDO8V, except ANOVR permits proportional as well as equal ns. All observations on the repeated-measures factors must be present for each subject used.

Output includes a check on the data as read, the summary table, and all possible means: cell means, means of two-factor slices and/or surfaces, main means, and so on. Homogeneity of independent cell variances is tested by Bartlett's test.

Designs with Subjects Crossed with Factors: RepeatedMeasures Designs (Winer, 1971, Chapter 4). ANOVR computes the variance-covariance (VCV) matrix on all repeated measures. The VCVs are often a source of psychological interpretations as well as of information indicating that the conventional assumptions of

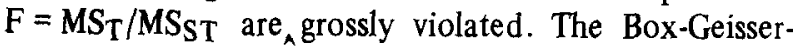
Greenhouse index, $\hat{\lambda}$, is computed on the VCV and is used to adjust the degrees of freedom so as to yield a robust F test (Winer, 1971, p. 523). The VCV is then rescaled to yield the correlations between the repeated measures.

Mixed Designs: Subjects Nested under Some Factors but Crossed with Other Factors (Winer, 1971, Chapter 7). In the simplest such design (Winer, 1971, p 518) with $a$ levels of the between factor and $b$ levels of the repeatedmeasures factor, there would be $a$ different $b$ by $b$ VCV matrices, one for each independent group. These are computed and printed or punched as requested; thus the variance is available for every cell. From each such matrix, a $\mathrm{MS}_{\mathrm{SB}}$ term is computed that would be the appropriate MSe for testing $\mathrm{MS}_{\mathrm{B}}$ computed on this group alone. Bartlett's test is used to test the homogeneity of these values (Winer, 1971, p. 522).

The a different VCV matrices are pooled and are tested for homogeneity by the Box technique (Winer, 1971, p. 595). The test for compound symmetry and the Machley test that $\lambda=1.0$ are conducted on the pooled VCV matrix.

For multifactor designs, mean squares needed for tests of means of one factor at a given level of another factor (Winer, 1971, p. 545) are computed. These features are not available in SPSS, SAS, BMD, or BMDP programs.

\section{Language}

The program is written in FORTRAN IV and compiles in WATFIV or FORTRAN (G or $\mathrm{H}$ ) on an IBM 370-168. Machine-specific features have been avoided.

\section{Computation Time and Space}

Most examples from Winer (1971) run in $3 \mathrm{sec}$. With the maximum number of options, the program occupies about $80 \mathrm{~K}$, plus some space for dynamic storage of the data array, $\overline{Y s}$, and VCVs. However, the program is available in reduced-option versions for smaller computers.

\section{Availability}

A copy of the program and documentation may be obtained by sending a standard tape to Paul A. Games, 420 Carpenter Building, University Park, Pennsylvania 16802 .

\section{REFERENCE}

Winkr, B. J. Statistical principles in experimental design (2nd ed.). New York: McGraw-Hill, 1971.

(Accepted for publication June 26, 1980.) 